\title{
Practice standards for quality clinical decision-making in nursing
}

\author{
E Arries, PhD \\ Faculty of Health, School of Nursing, University of Johannesburg
}

Keywords:

practice standards, quality clinical decision making

\section{Correspondence address:}

\section{Ebin Arries}

Senior Lecturer

Faculty of Health, School of Nursing

University of Johannesburg

PO Box 524

Auckland Park

2006

Tel : (011) 489-2707

Fax : (011) 489-2257

Email: ea@edcur.rau.ac.za

\section{Abstract: Curationis 29(1): $62-72$}

The purpose of this study is to formulate practice standards for quality clinical decisionmaking in nursing.

Clinical decision-making is a critical component of nursing practice, as the life of the patient is at stake. The quality of clinical decision-making is, therefore, essential in delivering quality nursing care. The facilitation of quality clinical decision-making in nursing requires the development of standards to monitor, evaluate and implement remedial actions that improve on the quality of clinical decision-making (Muller, 2002:203; Beyea \& Nicoll, 1999:495). However, there are no such practice standards against which the quality of clinical decision-making by nurses can be evaluated and assessed.

A qualitative, explorative, descriptive and standard formulation research design (Mouton \& Marais, 1990:45-46; Muller, 1990:49-55) has been followed to develop standards for quality clinical decision-making in nursing. Standard development was based on the principles described by Muller (in Booyens, 1998:607-608; 636-637), and consists of development and quantification phases that are modified to meet the requirements for instrument development, as described by Lynn (1986:382-385). The formulation of these practice-standards was derived deductively from a conceptual framework. The conceptual framework was constructed based on an exploration and description of the expectations of the stakeholders about quality clinical decisionmaking in nursing and a literature study on clinical decision-making. To ensure the credibility of the standards for clinical decision-making in nursing, principles of logic, prolonged engagement, triangulation, peer-group discussion, dense description, stepwise repetition and an investigative audit (Lincoln \& Guba, 1985:289-331) were adhered to. Two experts were consulted to validate the standards for quality clinical decisionmaking in nursing.

\section{Introduction}

The development and setting of quality standards are the first and most basic steps in the process of conducting quality assurance activities. In their Draft Charter for Nursing Practice, the South African Nursing Council (SANC, 2004:10) re-emphasise their commitment to the delivery of high quality nursing care by nurses. Clinical decision-making is a critical component of nursing practice. Nurses make daily clinical decisions that impact on the lives of their patients. The quality of these decisions therefore lies at the heart of the process to deliver quality nursing care. The achievement of such outcomes requires the development and implementation of mechanisms to facilitate the quality of clinical decision-making. One such mechanism that can be implemented to ensure the quality thereof, and therefore the quality of nursing care, is to formulate appropriate professional standards (Beyea \& Nicoll, 1999:495; SANC, 2004:29). In this vein, standard formulation is an essential activity of quality improvement.

The overall process of quality improvement includes the setting of standards, practice monitoring, the 
evaluation of identified practice problems, and resolving those practice problems (Muller, 2002:203). The development and use of standards are emphasised in the literature about the quality of care, as standards are used to derive criteria against which care, or the processes to deliver such care, are measured for the purposes of quality improvement (Dozier, 1998:22). Standards can be defined as statements relating to the scope of nursing practice, including both standards of care: aspects of the nurse's role such as assessment, planning and evaluation; and standards of professional performance, such as aspects of the nurse's role in quality assurance and research (American Nurses Association, 1991:1; Deab-Baar, 1993:33).

Bachman and Malloch (1998:26) also noted that the concept of standards carries with it incredible confusion. Based on a literature review, Patterson (1988:625) also found evidence of such confusion. She identified and defined two concepts that need clarification: standard of care and standard of practice. A standard of care focuses on the recipient of care (the patient) and a standard of practice focuses on the provider of care (the nurse). A standard of care is written about patient outcomes, whereas a standard of practice is written about the nursing process (Johnson \& McCloskey, 1992:53). Standards of practice are sometimes referred to as professional standards. Alternatively, standards can be classified as regulatory, voluntary and involuntary (Beyea \& Nicoll, 1999:495). Regulatory standards are based on regulation usually mandated by the government. Voluntary standards are those developed by health care practitioners and are often the work of a professional organisation. Both regulatory and voluntary standards can be paralleled with professional standards, which are promulgated by professional organisations, and accrediting and regulatory bodies and institutions (Dozier, 1998:22). Involuntary standards are those defined by professional liability insurance carriers. Standards may also be categorised according to the scope of influence, e.g. national, state, local or institutional standards (Beyea \& Nicoll, 1999:495). It is important to draw a distinction between a standard and clinical guidelines, as these concepts are often confused or used interchangeably. Standards are different from guidelines.
By comparison, guidelines refer to recommended approaches to managing patient/client conditions, focusing on specific aspects of patient care delivery connecting interventions and expected outcomes (Dozier, 1998:23). Clinical practice guidelines are statements designed to assist practitioners with decision-making about appropriate care for specific clinical circumstances. Clinical guidelines reflect the state of current clinical knowledge, as published in the scientific health care literature, regarding the effectiveness and appropriateness of procedures or practices (Child \& Holmes, 1999:73). However, both guidelines and standards can serve as the basis for many activities, either within nursing or the larger healthcare system. Guidelines reflect standards. They describe care delivery that is consistent with standards. Both can enhance multidisciplinary collaboration (Childs \& Holmes, 1999:74).

Decision-making is a process carried out by the nurse (the provider of care), but it is focused on the patient (the recipient of care). In this vein, decision-making forms part of the nurse's daily practice. Therefore, standards for quality clinical decision-making can be regarded as practice standards, as they focus on the functions of the provider of care. Practice standards on decision-making in nursing refer to descriptive statements that reflect the minimum expected level of care and that settle disputes about the expected level of performance during a nurse's clinical decision-making.

The importance of quality in health care has become more marked in the past few years. Measures to improve the quality of care, in the context of the reduced availability of health care staff, have led to the questioning of the accepted boundaries of professional roles. One such role in question is that of the nurse as decision-maker. The need to improve the quality of clinical decision-making in nursing is one of the most serious issues facing present clinical nursing practice. Effective and efficient decision-making practices are emphasized in the White Paper on the Transformation of Public Services (1997) in order to achieve a highly efficient public service, including healthcare services. Decision-making forms an integral part to attain the latter. However, the quality of the decisions taken determine whether an efficient health care service is attainable. The incredible amount of healthcare data, complex and continuing regulatory changes and, most importantly, the erosion of public confidence in health care quality require significant action. In this vein, Malloch (1999:1) indicates that selected strategies must address the quality control needs and the unprecedented demands placed on health care leaders. This is particularly relevant to the service-delivery point in the healthcare sector, where nurses' clinical decisions have a direct impact on the health status of the patient. Thus, developing quality control programmes that identify, monitor and document quality outcomes is essential to restore public trust and confidence in healthcare. To do so, a collaborative approach to health care decision-making in general, but to clinical decision-making in particular, is required.

Clinical decision-making is both a cognitive and an affective problemsolving activity that focuses on defining patient problems and selecting appropriate treatment interventions (Buckingham \& Adams, 2000:981; Deloughery, 1998:47). In a clinical nursing practice setting, nurses work as members of a healthcare team and must communicate decisions to other members of the multi-disciplinary healthcare team to ensure the continuity and coordination of patient care. Therefore, cooperative and collaborative efforts during clinical decision-making should be emphasised and reflected in standards of professional practice in terms of clinical decision-making.

Nurses form the largest proportion of the healthcare delivery resources in the Kealthcare sector. They therefore play an important role in the delivery of quality healthcare, in general, and in nursing care, in particular. Quality clinical decisionmaking is an important process through which the nurse delivers nursing care. Quality clinical decision-making in nursing refers to a rational, interactive, collaborative, consultative and scientifically-based process. During this process, nurses make goal-directed choices between perceived alternatives, based on their abilities, within a specific context, with the purpose of promoting the health of the individual, group or community. These choices coincide with predetermined standards (Arries, 2002:308; Noone, 2002:21-22). The quality of decision-making will influence 
the quality of the outcome, viz. health promotion and empowerment of the individual, group or community. In addition, not only does the nurse's quality of clinical decision-making influence the outcome thereof, but it also has financial implications for the institution at large. Furthermore, the nurse, as a so-called independent practitioner, is not only responsible and accountable for quality clinical decisionmaking to facilitate quality nursing specifically, but also for quality healthcare in general. The nurse therefore requires practice guidelines on clinical decisionmaking that reflect excellence and are presented in the form of standards and criteria that are user-friendly and realistic.

\section{Problem statement}

Clinical decision-making in nursing is regarded as an important activity by the nurse, since a decision is a prerequisite for any significant action by the nurse to care for the patient. However, from unstructured observation by studying the South African Nursing Council's (1993-1998) disciplinary reports, the following about nurses' clinical decisionmaking has been observed: (i) an increase in the number of disciplinary cases among nurses, and (ii) that these disciplinary cases reflect situations within which the nurse had made decisions to either maintain, restore or promote the health of the patient. It was however concluded from these observations that nurses' clinical decision-making is ineffective, as it does not adhere to the framework of clinical, ethical and legal correctness for any nursing action, including clinical decision-making.

As a possible solution to the aforementioned problem, practice standards for quality clinical decision-making in nursing are required. The aim of these practice standards should be to evaluate, monitor and remedy actions implemented to improve the quality of clinical decisionmaking, a process nurses follow during patient care.

However, there are no such practice standards in the South African context, against which one can evaluate and assess nurses' quality of clinical decision-making.

\section{Purpose of the study}

The purpose of the study is to formulate practice standards for quality clinical decision-making in nursing.

\section{Definition of terms}

\section{Practice standards}

Practice standards focus on the provider of care (the nurse) and are written about the nursing process. A practice standard on clinical decision-making is a written description about the desired level of performance during clinical decisionmaking that reflects the connotative characteristics associated with excellence for measuring and evaluating the actual quality thereof (Muller in Booyens, 1998:606; Dozier, 1998:23).

\section{Quality}

Defining the term quality is almost an impossible task, as it has a multifaceted nature (Davis, 1987 in Johnson \& McCloskey, 1992:45). For the purposes of this study, quality is defined as reflecting the characteristics of excellence as described in predetermined standards.

\section{Quality clinical decision-making}

Quality clinical decision-making, a cognitive-affective problem-solving activity, refers to the outcomes of rational interactive collaborative and consultative dynamic problem-solving processes, in which nurses and members of the multidisciplinary health team engage to define patient problems, to select and implement appropriate treatment interventions, and to communicate decisions in accordance with predetermined standards to ensure the quality, continuity and coordination of patient care in order to facilitate health (Arries, 2002:308).

\section{Research design and method}

A qualitative, explorative, descriptive standard formulation research design (Mouton \& Marais, 1990:45-46; Muller, 1990:49-55) has been followed to develop standards for quality clinical decisionmaking in nursing. Standard development requires a unique method.

Standard development was based on the principles described by Muller (in Booyens, 1998:607-608; 636-637), and consists of development and quantification phases that are modified to meet the requirements, as described by Lynn (1986:382-385), for instrument development. The development phase requires input from expert and grassroot level practitioners. The purpose is to determine what specialists in the various fields of nursing practice regard as good practice. Both inductive and deductive approaches can be employed to achieve the latter and ensure ownership and trustworthiness of the standards. The quantification phase deals with the formal validation of the draft standard and the evaluation of the level of performance in nursing practice.

The above process of standard development was modified in this study. The quantification phase was omitted, as the researcher argued that by following the principles of logical deduction and induction, credible and reasonable standards could also be formulated. Both inductive and deductive approaches were followed during this process. See Table 1.

The research was conducted in four phases, namely an empirical phase, a conceptualisation phase, a standard formulation phase and the last phase was the conceptualisation of a system for quality clinical decision-making in nursing. These four phases will be described in detail below.

Phase 1: empirical phase

To meet the first criterion proposed by Muller (in Booyens, 1998:607), that is, input from expert and grassroot level practitioners, empirical exploration and description of the expectations of the stakeholders in terms of quality clinical decision-making were carried out (see Table 1). To obtain richness in data about the expectations of these stakeholders, a multi-method approach was followed. Focus group interviews (Kreuger, 1994:39-74; De Vos, 1998:313-324), individual interviews (De Vos, 1998:297312) and naive sketches (Giorgi, 1985:1014) were employed. A non-probability, purposive and convenient sample (Burns \& Grove, 2001:374; De Vos, 1998:199) of the stakeholders was conducted. Data was analysed by means of the open coding approach described by Tesch (Tesch, 1990). To ensure the credibility of the results of the first phase, principles of trustworthiness (Lincoln \& Guba, 1986:289-331), viz. prolonged engagement, triangulation, co-coding, dense-description, step-wise repetition and an investigative audit, were adhered to.

Phase 2: conceptualisation phase

During the conceptualisation phase, a concept analysis (Walker \& Avant, 1995:390) on quality clinical decision- 
PHASE ONE: Empirical phase: Expectations of the stakeholders

Method of data collection:

Focus group interviews (Kreuger, 1994:39-74; Morgan, 1998:55-121; De Vos, 1998:313-324), naïve sketches (Giorgi, 1985:10-14); individual unstructured interviews (De Vos, 1998:297-312)

\section{Population and sampling}

Non-probability, purposeful and convenient sampling (Burns \& Grove, 2001:374; De Vos, 1998:199) of the different stakeholders (clinical nurse practitioners, nurse educators, doctors, nurse managers)

\section{Method of data analysis}

Open coding (Tesch, 1990)

\section{Trustworthiness}

Methods of trustworthiness (Lincoln \& Guba, 1985:289-331)
PHASE TWO: Conceptualisation of quality clinical decisionmaking in nursing Method of data collection:

Literature study; concept analysis (Walker \& Avant, 1995:390)

\section{Population and sampling}

Non-probability, purposeful sampling (Burns \& Grove, 2001:376) of national and international sources (journals, dictionaries, thesauruses, books)

\section{Method of data analysis}

Deductive and inductive thinking strategies (Mouton \& Marais, 1990:104-106; Mouton, 1996:74-79; Van Veuren, 1993:276-278; Giere, 1984:33-46)

\section{Trustworthiness}

Theoretical validity (Copi \& Cohen, 1994:192-196); standards for good conceptualisation (FUNDISA, 2000)

PHASE THREE: Formulation of standards

Research method:

- Standard formulation (Muller, 1990)

Method of data analysis

- Logic of deductive and inductive inference (Mouton, 1996:77-79)

Strategies for trustworthiness

- Lincoln and Guba (1985:289-331)

PHASE FOUR: A system for quality clinical decision-making nursing

Research method:

- Conceptualisation

- Characteristics of a system according to systems theoretical perspective (Bertallaffny, 1950)

Trustworthiness

Standards of good conceptualisation (FUNDISA, 2000) 
making was carried out. A purposeful selection (Burns \& Grove, 2001:376) of both national and international literature sources, viz. thesauruses, journal articles and subject-specific literature on the themes that emerged from the empirical phase, was conducted. The aim of the literature study was twofold, on the one hand to analyse the concept's quality and clinical decision-making respectively and, secondly, to integrate the results with those of the empirical phase in a conceptual framework, by employing both inductive and deductive reasoning strategies.

This conceptual framework was used as a deductive guide to formulate the standards for quality clinical decisionmaking in nursing. To ensure the trustworthiness of the conceptualisation, principles for credible conceptualisation (FUNDISA, 2000), together with triangulation and scheduled peer group discussions, were employed.

\section{Phase 3: standard formulation phase}

During the third phase, practice standards for clinical decision-making in nursing were formulated. The formulation of these practice standards was based on the statements logically derived from the conceptual framework. By employing reasoning strategies of analysis, synthesis and inference, practice standards for quality clinical decision-making were derived inductively and deductively. To ensure the credibility of the standards for clinical decision-making in nursing, principles of logic, prolonged engagement, triangulation, peer-group discussion, dense description, step-wise repetition and an investigative audit (Lincoln \& Guba, 1985:289-331) were applied. Two experts on standard formulation in nursing were also consulted during this process.

\section{Phase 4: a system for quality clinical decision-making in nursing}

Based on the findings of the preceeding phases, a system for quality clinical decision-making in nursing was conceptualised. Figure one is the conceptual presentation of this system (see Figure 1).

Before embarking on a description of the standards for quality clinical decisionmaking, a description of the conceptual framework, on which the standards are based, is given.

\section{Conceptual framework: Quality clinical decision- making in nursing}

Standards can be derived from different sources based on frameworks as diverse as the nursing process, health care needs, body systems or the process of care. Standard development is based on a conceptual framework of a system for quality clinical decision-making in nursing (Figure 1).

Quality clinical decision-making in nursing occurs in a multi-level, multidimensional context. The multidimensional nature of the context within which clinical decision-making occurs has several uncontrolled dimensions that influence the quality thereof. It is therefore important for the nurse to consider these dimensions during clinical decision-making. The context of quality clinical decisionmaking brings about certain expectations of the stakeholders involved in such a decision. In nursing, stakeholders regard factors such as abilities (knowledge, skills and values) and resources (including both material and human resources) as important inputs for quality clinical decision-making. These inputs are transformed during the process of clinical decision-making into outcomes, viz. the promotion of health and the empowerment of the individual, group or community. Argumentation, the logic of quality clinical decision-making, requires a rational interactive approach. This implies that the nurse engages in dialogue with other appropriate healthcare professionals through a process of collaboration, consultation and argumentation. Rational argumentation refers to a communicative and collaborative process of advancing, supporting, criticising and modifying claims, and the reciprocal statement of arguments that all stakeholders are capable of understanding so that they may grant or deny adherence (Rossouw, 1993:293).

Through a process of rational interaction, collaboration and consultation, nurses engage with members of the multidisciplinary health team to define patient problems, select and implement appropriate treatment interventions, and communicate decisions in accordance with predetermined standards to ensure the quality, continuity and coordination of patient care (Arries, 2002:308). The aim of this interaction is to promote the health of the individual, group or community through empowerment.

\section{Practice standards for clinical decision-making in nursing}

Practice standards for clinical decisionmaking in nursing will be presented. The nurse, as a provider of healthcare, is an independent practitioner who makes clinical decisions in collaboration with a multi-professional health team. As a decision-maker, the nurse synthesises theoretical, scientific and contemporary clinical knowledge and experience to assess the health status of the individual, group or community, and to promote their health and empowerment on the wellness-illness continuum of health.

I have indicated elsewhere in this article that practice standards focus on the nurse as a provider of nursing care. Therefore, these standards are sometimes referred to as professional practice standards. Unlike standards of care that focus on the individual patient and his/ her specific health status, and using an accepted scientifically-based process such as the nursing process to address his/her health problems, standards of professional practice relate to the professional behaviour of the nurse while doing that, and particularly using the process of clinical decision-making. The intention of professional practice standards on quality clinical decisionmaking is to provide direction for nursing practice regardless of the practice setting. Standards of professional practice usually involve dimensions of quality of care, performance appraisal, education, collegiality, ethics, collaboration, research and the utilisation of resources (Childs \& Holmes, 1999:74). Practice standards for quality clinical decisionmaking in nursing will be discussed under two main clusters: those that relate to professional practice, the clinical decision-making process and empowerment as the outcome of the latter. The dimensions listed by Child and Holmes (1999:74) are integrated in the aforementioned clusters, for the sake of simplicity and understanding.

\section{Professional practice}

Practice standards about professional practice related to the macro-, meso-, and microdimensions of the context within which clinical decision-making takes 


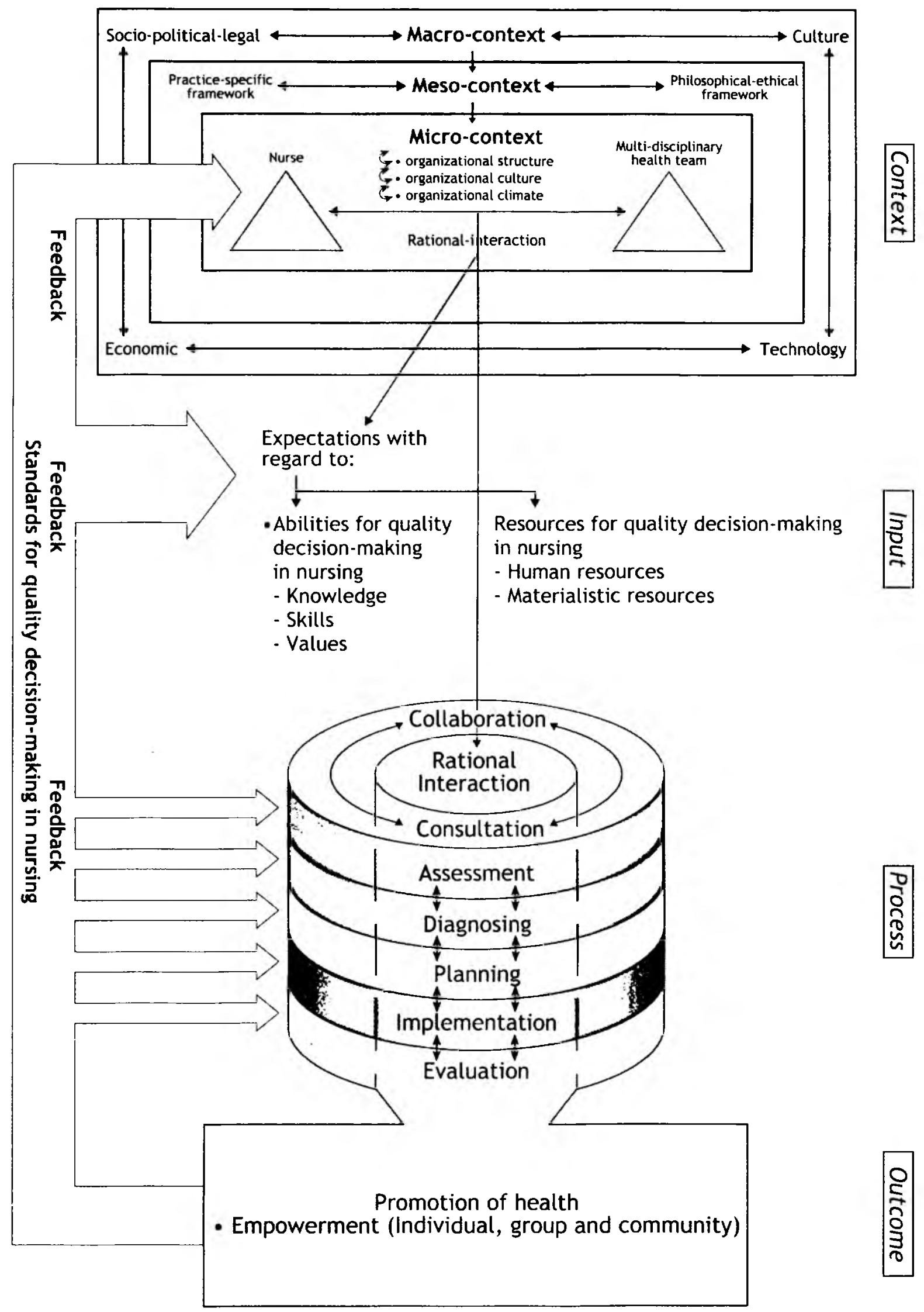

Figure 1: A System for quality decision-making in Nursing 
place (see Figure 1), and the competencies possessed by the nurse to ensure quality clinical decision-making. 1.1 Clinical decision-making occurs in congruency with the socio-political, legal, economic, cultural and technological context of nursing practice and heath care. The nurse:

1.1.1 knows and understands the legal, ethical, economic and clinical implications of relevant legislation, and the policies and procedures of clinical decisionmaking;

1.1.2 functions within the legally recognised scope of practice of nursing and within all relevant legislation;

1.1.3 follows and/or assists in developing institutional policies and evidence-based care standards and guidelines applicable to the context of clinical decision-making; and

1.1.4 takes suitable action to promote the provision of safe, appropriate and ethical clinical decisions.

1.2 Clinical decision-making takes place in the relevant professional practicespecific framework of nursing practice: The nurse:

1.2.1 demonstrates insight and can describe relevant legislation, standards, policies and procedures that affect his/ her clinical decisions as a nurse;

1.2.2 demonstrates responsibility and accountability for own clinical decisions and professional conduct;

1.2.3 demonstrates a commitment to ethical practice and a responsible attitude towards patients/families/members of the multidisciplinary team;

1.2.4 maintains current registration as a nurse;

1.2.5 practises clinical decision-making within his/her own level of clinical competence;

1.2.6 meets the requirements for continuing clinical competence with regard to clinical decision-making and nursing practice, including investing own time, effort or other resources to meet identified learning outcomes;

1.2.7 maintains own physical, psychological and emotional fitness for nursing practice;

1.2.8 continually identifies, monitors, and documents evidence of clinical decisionmaking practice accurately and legally in relation to legislation and policies;

1.2.9 continuously refines and adapts practices of clinical decision-making to conform to legislation, standards and policies; and

1.2.10 identifies and understands the legal-ethical and clinical implications of his/her clinical decisions.

1.3 The nurse applies relevant professional ethics and philosophical frameworks to clinical decision-making. The nurse:

1.3.1 describes the ethical standards established by the respective professional or registering body relevant to clinical decision-making;

1.3.2 upholds the values contained in the South African Nursing Council (SANC) Code of Ethics, namely safe, competent and ethical care, choice, dignity, confidentiality, justice, accountability and quality practice environment;

1.3.3 consistently demonstrates ethical attitudes, values and behaviours that are conducive to ethical clinical decisionmaking and practice;

1.3.4 consistently practises according to the responsibility and accountability statements in the SANC Code of ethics; 1.3.5 identifies key strategies to resolve ethical dilemmas arising from clinical decisions;

1.3.6 critically reflects on the morality of clinical decisions and incorporates current evidence on moral reasoning in clinical decision-making;

1.3.7 is committed to his/her own professional development as a clinical decision-maker; and

1.3.8 demonstrates a commitment to confidentiality and respect for diversity.

1.4 The clinical context (micro-context) is conducive to rational interaction during clinical decision-making.

1.4.1 The nurse understands the context and systems in which healthcare is provided, and applies this knowledge to optimise healthcare.

1.4.2 The organisational structure, culture and climate are conducive to rational, interactive and collaborative clinical decision-making.

1.4.3 There is evidence of applicable collaboration, consultation and cooperation among members of the multidisciplinary health team.

1.4.4 There is evidence of continuous empowerment strategies to develop nursing staff's clinical decision-making competencies.

1.4.5 There is evidence of written, relevant and up-to-date policies, guidelines, protocols and procedures that guide clinical decision-making.

1.4.6 The nurse recognises the interdependence between diverse care providers while understanding the limitations and opportunities inherent in complex systems.

1.4.7 There is evidence of cost-effective strategies that ensure the availability of relevant resources to enhance the quality of clinical decision-making.

1.4.8 The nurse considers factors related to safety, effectiveness and cost in planning and clinical decision-making.

1.5 The nurse demonstrates appropriate and relevant clinical competencies (specialised body of knowledge, skills and values) and utilises evidence from nursing science and the humanities to make clinical decisions..

The nurse:

1.5.1 knows how and where to find relevant evidence to support the making of safe, appropriate and ethical clinical decisions;

1.5.2 interprets and uses current evidence from research and other credible sources to make clinical decisions;

1.5.3 understands and communicates nursing contribution to clinical decisionmaking in health care practice;

1.5.4 shares nursing knowledge about clinical decision-making with patients, colleagues, students and others;

1.5.5 uses relationship and communication theories appropriate in interaction with colleagues, patients and others; and

1.5.6 interprets and uses current evidence from research and other credible sources to make clinical decisions.

\section{Clinical decision-making}

Rational clinical decision-making is believed to refer to an interactive process of assessment, diagnosis, planning, implementation and evaluation.

\section{(i) Assessment}

2.1. The nurse performs a comprehensive functional, relevant and holistic assessment using a developmental, biopsycho-social approach, as the framework for understanding the nature of health problems patients present with.

\section{The nurse:}

2.1.1 obtains and accurately documents a relevant, comprehensive and problemfocused health history, considering both bio-psycho-social and cultural changes; 2.1.2 assesses the dynamic interaction between the current complaint and the known acute/ chronic health problems, in accordance with developmental status; 2.1.3 performs and accurately documents a comprehensive and problem-focused 
physical examination, considering both bio-psycho-social and cultural changes; 2.1.4 assesses and accurately documents relevant, comprehensive and problemfocused laboratory and diagnostic data, considering bio-psycho-social and cultural changes;

2.1.5 performs appropriate screening evaluations that are age, gender and development specific (including mental health, substance abuse, violence, behaviour, speech/language development, learning disabilities, etc.);

2.1.6 analyses the multiple effects of pharmacological agents, including homemade remedies and shop-purchased preparations, relating to the individual/ group/community with health problems; 2.1.7 performs and accurately assesses and documents the impact of the environment on the health status of the individual, group, family or community, considering bio-psycho-social and cultural changes;

2.1.8 identifies health and bio-psychosocial and environmental risk factors for the individual, group or community (including developmental level, risktaking behaviour, nutritional status, environmental factors, family issues, social support and immunisation status); 2.1.9 analyses roles, tasks and stressors of formal/informal systems/family caregivers for the individual, particularly for vulnerable and frail groups;

2.1.10 discriminates between multiple potential mechanisms causing signs and symptoms of health problems commonly diagnosed in the individual/group/ community; and

2.1.11 analyses and synthesises the data collected to determine the health status of the individual/group/community.

\section{(ii) Diagnosis}

2.2 The nurse formulates an accurate, valid and comprehensive/specific health problem/differential diagnosis, congruent with the assessment data.

The nurse:

2.2.1 systematically compares and contrasts clinical findings with normal and abnormal variations in formulating a diagnosis or differential diagnosis;

2.2.2 documents evidence pointing to the utilisation of the complex assessment data and information obtained during health history interview, physical examination and laboratory and diagnostic procedures in formulating a diagnosis;

2.2.3 documents diagnosis in a manner that facilitates the determination of the expected outcomes for the individual, group or community;

2.2.4 derives the diagnosis that is logical and congruent with the assessment data; and

2.2.5 when possible and appropriate, documents evidence that has validated the diagnosis with other health care professionals.

\section{(iii) Planning}

2.3 The nurse formulates an appropriate individualised plan of care that prescribes strategies and alternatives to attain written expected outcomes and objectives.

2.3.1 The plan of care relates to the health needs and problems of the individual, group or community.

2.3.2 Documented evidence about the expected outcomes of the care plan can be identified.

2.3.3 The plan incorporates specific health outcomes for the individual or group or the special needs or problems of the community.

2.3.4 When possible and appropriate, evidence is documented that the individual/group/community and other health care professionals were consulted and involved in formulating the expected outcomes.

2.3.5 The plan of care reflects current legal-ethical frameworks (Acts, rules, protocols and regulations) and research on evidence-based findings.

2.3.6 The plan is documented using standardised language and recognised terminology.

2.3.7 The plan reflects the synthesis of stakeholders (patients, nurses and other relevant health professionals), and their expectations, values and beliefs in terms of nursing practice.

2.3.8 The plan derives expected outcomes congruent with the formulated diagnosis and demonstrates clinical, legal-ethical and cultural correctness.

2.3.9 It identifies expected outcomes while considering the associated risks, benefits, costs and current scientific and clinical practice knowledge.

2.3.10 Expected outcomes are congruent with the patient and environmental/ situational expectations.

2.3.11 Expected outcomes delineate a time frame for attainment.

2.3.12 Expected outcomes provide direction for the continuation of care.

2.3.13 Documented evidence on modifications of the expected outcomes is based on changes in the health status of the patient/evaluation of the situation.
2.3.14 Expected outcomes reflect scientific evidence and are achievable through the implementation of evidencebased practice.

2.3.15 Expected outcomes are documented as measurable objectives.

2.3.16 The plan includes strategies that address each of the formulated expected outcomes.

\section{(iv) Implementation}

2.4 The nurse implements the identified plan of care in a legal-ethical, clinically correct and culturally congruent manner: 2.4. 1 The nurse co-ordinates the delivery of care by:

2.4.1.1 employing strategies to promote the health and safety of the environment; 2.4.1.2 providing leadership in coordination with multidisciplinary health teams for delivering an integrated patient care service.

2.4.1.3 synthesising data and information to advocate the necessary system and community support measures, including environmental modifications; and 2.4.1.4 coordinating resources to enhance the delivery of care across the multidisciplinary healthcare continuum.

2.4.2 The nurse collaborates with other members of the multidisciplinary health team/patients/families in the identified plan of care, to enhance the abilities of others and to affect change by:

2.4.2.1 functioning as a member of the multidisciplinary health team to provide nursing expertise;

2.4.2.2 integrating the treatment plan with the goals of the multidisciplinary health team;

2.4.2.3 maintaining responsibility for the more specialised health treatment plan goals and communicating these goals to the rest of the multidisciplinary health team:

2.4.2.4 synthesising clinical data, experience and theoretical frameworks and evidence when providing consultation;

2.4.2.5 facilitating the effectiveness of consultation and collaboration by involving the relevant stakeholders in decision-making and negotiating role responsibilities;

2.4.2.6 communicating consultation and collaborative recommendations that influence the identified plan, facilitating understanding among stakeholders, enhancing the work of others and affecting change;

2.4.2.7 collaborating with nursing colleagues and other healthcare 
personnel to implement the care plan, if appropriate;

2.4.2.8 supporting collaboration with nursing colleagues and other members of the health team to implement the plan of care;

2.4.2.9 establishing and sustaining therapeutic and ethically sound relationships with patients/families/ members of the multidisciplinary health team;

2.4.2.10 advocating and developing policies that clearly outline responsibility and accountability for everyone involved in clinical decision-making; and

2.4.2.11 communicating, collaborating and consulting with registered nurses and other members of the healthcare team about the provision of healthcare services.

2.4.3 The nurse consults with other members of the multidisciplinary health team during the identified plan of care to enhance the abilities of others and to effect change by:

2.4.3.1 consulting with colleagues and other members of the multidisciplinary health team on specific cases/issues;

2.4.3.2 describing the types of case consultation;

2.4.3.3 selecting the appropriate method for consultation;

2.4.3.4 determining the need for further information and support;

2.4.3.5 suggesting appropriate options or alternatives to existing services or clinical approaches;

2.4.3.6 providing general consultation and education on individual health issues;

2.4.3.7 assessing the need for education; 2.4.3.8 developing educational resources for use by patients/families and the community;

2.4.3.9 integrating adult education principles in the delivery of education; and

2.4.3.10 responding to requests for information from the patient/family/ community.

2.4.4. The nurse implements the identified plan of care in a safe, timely and appropriate manner by:

2.4.4.1 utilising evidence-based interventions or treatments unique to the needs of the individual/group/ community;

2.4.4.2 utilising appropriate resources in a cost-effective manner to implement the plan;

2.4.4.3 facilitating the utilisation of resources to implement the plan;

2.4.4.4 incorporating new knowledge and strategies that are appropriate to initiate change in nursing care practice if the desired outcomes are not achieved;

2.4.4.5 implementing the plan of care by utilising the principles and concepts of project/systems management;

2.4.4.6 maintaining comprehensive, timely and legible records;

2.4.4.7 guiding and supervising staff and others involved in the implementation of clinical decisions;

2.4.4.8 advocating, directing and participating in changes to improve clinical decisions and patient care;

2.4.4.9 taking appropriate action and reporting unsafe clinical decisions or professional misconduct pertaining to clinical decision-making;

2.4.4.10 assisting patients, colleagues, students and others to learn about clinical decision-making and nursing practice;

2.4.4.11 interpreting research evidence to guide clinical decisions and the development of an appropriate plan of care; and

2.4.4.12 advocating and participating in changes that promotes evidence-based clinical decision-making, nursing care and improved conduct of research in clinical decision-making.

\section{(v) Evaluation}

2.5 The nurse evaluates progress in the attainment of outcomes by:

2.5.1 conducting a systematic, ongoing and criterion-based evaluation;

2.5.2 systematically evaluating outcomes in relation to the structure and processes prescribed by the plan;

2.5.3 including the individual, group or community involved in the care/situation in the evaluative process;

2.5.4 using ongoing assessment data to revise the diagnosis, the outcomes and the plan, as needed;

2.5.5 evaluating the effectiveness of the planned strategies in relation to patient responses and the attainment of the expected outcome;

2.5.6 documenting and disseminating, as appropriate, the results of the evaluation, including any need for managerial action; 2.5.7 evaluating the accuracy of the diagnosis and the effectiveness of the interventions in relation to the patient's attainment of the expected outcome; 2.5.8 synthesising the results of the evaluation analyses to determine the impact of the plan on the affected individual, group or community; and
2.5.9 using the results of the evaluation analyses to make recommendations to process or structure changes, including policy, procedure or protocol documentation, as appropriate.

\section{Outcome: empowerment}

3.1 There is written evidence that clinical decision-making in nursing facilitates the empowerment of the individual, group or community, as measured by the following criteria:

3.1.1 Individuals, groups or communities are able to make informed decisions about identifying and prioritising problems that affect them.

3.1.2 They are able to identify and challenge factors that render them powerless during decision-making.

3.1.3 They have developed leadership skills that enable them to sustain health promotion.

3.1.4 They have increased confidence and competence in handling decisions that affect them.

3.1.5 They are able to sustain health promotion even after outside help is withdrawn.

3.1.6 They have established their own decision-making support networks and therefore rely less on outside help and formal structures.

3.1.7 They are able to communicate identified needs to decision-makers.

3.1.8 They have developed effective communication skills and are able to solve conflict during decision-making

\section{Critique of the standards}

Developing standards requires a structured approach that can incorporate either an empirical or a normative approach.

\section{Empirical approach}

The empirical approach, also called the inductive approach, requires a survey of what is currently regarded as good practice in similar circumstances (Muller, 2002:206). To achieve these criteria, the expectations of stakeholders in terms of quality clinical decision-making in nursing were explored and described. Based on these results, principles for standard formulation were generated by using the inductive and deductive reasoning strategies of analysis, synthesis and inference.

\section{Normative approach}

In the normative approach, the objective is to determine what specialists in the 
various fields regard as good practice (Muller, 2002:206). In other words, what ought to happen during clinical decisionmaking. These criteria were met by conducting a literature study on clinical decision-making, i.e. structure, process and outcome. Again, based on these results, principles for standard formulation were generated using the inductive and deductive reasoning strategies of analysis, synthesis and inference.

In following the two above processes, it was ensured that reasonable standards were formulated based on what is considered to be "right" inside and outside nursing. A conceptual framework was thus constructed, based on the results of the empirical and normative approaches. The general value system, as set out in the philosophical, legal and ethical framework of nursing, also gives direction to what could be considered to be right and wrong during clinical decision-making.

Standards for quality clinical decisionmaking met the following criteria. They are realistic, understandable, manageable and achievable.

\section{Realistic standards}

The standards are realistic as they were inferred from both empirical and conceptual data. Consensus discussion with two experts on standard formulation confirms the realistic nature of these standards.

\section{Understandable, manageable and achievable standards}

The standards are understandable, as they are written in a language known to local nurses in the country. During the literature study phase it was ensured that language and nuances in meaning were overcome through the re-interpretation of the structure, process and outcome of clinical decision-making as it operates within nursing.

Thirty-six standards for quality clinical decision-making in nursing were initially formulated (Arries, 2002:327-354). Following the recommendations of experts on standard formulation, and considering the criteria of manageability and achievability, these standards were re-organised and categorised. The thirtysix standards were reduced to twelve standard statements, each with its own criteria for measurement.

\section{Conclusion and}

\section{recommendations}

Practice standards for quality clinical decision-making in nursing were developed. These standards were based on the expectations of stakeholders regarding quality clinical decisionmaking in nursing and an in-depth literature study. In employing the rules of inductive and deductive logic, it is believed that reasonable standards of trustworthiness, based on the empirical findings of the expectations of stakeholders and the conceptualisation of clinical decision-making, were developed. The following recommendations on how these standards could be used to guide clinical decision-making in nursing are made:

\section{(i) Nursing practice}

(a) Standards for quality clinical decisionmaking could be utilised as a foundation for interdisciplinary and interinstitutional consensus building.

(b) By defining the scope of clinical decision-making for nurses, these standards could be utilised as an infrastructure for the development of institutional standards of care and guidelines.

(c) Using these standards to link key concepts such as clinical decisionmaking, the contextual dimension thereof, ethics and empowerment outcomes could be utilised as a foundation to reduce fragmentation.

(ii) Nursing education, management and research

(a) By defining the scope of clinical decision-making, these standards could be utilised as an infrastructure for the competency-based education programmes;

(b) The standards can be utilised to develop educational sessions and for curriculum development emphasising competencies for clinical decisionmaking in nursing.

(c) These standards can be utilised to plan, organise, and evaluate clinical decision-making practices in nursing.

(d) Lastly, these standards can be utilise to evaluate and enhance multidisciplinary collaboration during clinical decision-making among healthcare professionals.

\section{References}

AMERICANNURSES' ASSOCIATION,

1991: Task force on nursing practice standards and guidelines: Working Paper. Journal of Nursing Ouality Assurance. 5(3):1-17.

ARRIES, EJ 2002: 'n Sisteem vir gehaltebesluitneming in verpleging. Johannesburg: Randse Afrikaanse Universiteit. (D.Cur Proefskrif)

BACHMAN,JP \& MALLOCH, K 1998: Developing a common nursing practice model. Nursing Management. 29(1): 2627.

BERTALANFFY, L 1950: The theory of open systems in physics and biology. (In: Emery, FE Eds. 1969: Systems thinking: selected readings. England: Penquin Books, pp 23-68).

BEYEA, SC \& NICOLL, LH 1999: When research cannot answer a question: Standards of care. Association of Operating Room Nurses. AORN Journal. 70(3):495-497.

BOOYENS, SW 1998: Dimensions of nursing management. Second edition. Kenwyn: Juta.

BUCKINGHAM, CD \& ADAMS, A 2000: Classifying clinical decisionmaking: A unifying approach. Journal of Advanced Nursing. 32:981-989.

BURNS, N \& GROVE, SK 2001: The practice of nursing research: Conduct, critique and utilization. Fourth edition. Philadelphia: WB Saunders.

CHILDS, SG \& HOLMES, SB 1999: Guidelines for orthopedic nursing: Adult trauma. Orthopedic Nursing. 18(1):73-78.

COPI, IM \& COHEN, C 1994: Introduction to logic. Ninth edition. New York: McMillan.

DEAB-BAAR, SL 1993: Application of the new ANA framework for nursing practice standards and guidelines. Journal of Nursing Care Ouality. 8(1):3342.

DELOUGHERY, SD 1998: Clinical decision-making: Theory and practice. Nursing Standard. 18(36):47-52.

DE VOS, AS Eds. 1998: Research at grass roots: A primer for the caring professions. Pretoria: Van Schaik Publishers.

DOZIER, AM 1998: Professional 
standards: Linking care, competence, and quality. Journal of Nursing Care Ouality. 12(4): 22-29.

FUNDISA, 2000: (Unpublished). Standards for good conceptualisation in research. Johannesburg: Department of Nursing Science.

GIERE, RM 1984: Undertsanding scientific reasoning. Second edition. New York: Holt, Rhinehart and Winston.

GIORGI, A 1985: Phenomenology and psychological research. Pittsburgh: Duquesne University Press.

JOHNSON, M \& MCCLOSKEY, JC 1992: The delivery of quality health care. Series on Nursing Administration, 3. St Louis: Mosby Year Book.

KRUEGER, RA 1994: Focus groups: A practical guide for applied research. Second edition. London: Sage Publication.

LINCOLN, YS \& GUBA, EG 1985: Naturalistic inquiry. New York: Sage.

LYNN, NR 1986: Determination and quantification of content validity. Nursing Research. 35(6): 382-385.

MALLOCH, K 1999: The performance measurement matrix: A framework to optimise decision-making. Journal of Nursing Care Ouality. 13(3): 1-12.

MORGAN, LD 1998: Planning focus groups. London: SAGE Publication.

MOUTON, J \& MARAIS, HC 1990 : Metodologie vir die geesteswetenskappe: Basiese begrippe. Pretoria: Raad vir Geesteswetenskaplike Navorsing.

MOUTON, J 1996: Understanding social research. Pretoria: Van Schaik.

MULLER, M 1990: Navorsingsmetodologie vir die formulering van verpleegstandaarde. Curationis, 13(3 \& 4): 49-55.

MULLER, M 2002 : Nursing dynamics. Third edition. Sandown: Heinemann.

NOONE, J 2002: Concept analysis of decision-making. Nursing Forum, 37(3):21-32.

PATTERSON, C 1988: Standards for patient care: The Joint Commission focus on nursing quality assurance. Nursing Clinics of North America. 23: 625-638.

SOUTH AFRICA (REPUBLIC) 1997: White Paper on the transformation of public service delivery (Batho Pele). Notice 1459 of 1997: Pretoria: State Press.

ROSSOUW, GJ 1993: Moral decisionmaking amidst moral dissensus: A postmodern approach to moral decisionmaking in business. Koers. 58(3): 283298.

SOUTH AFRICAN NURSING COUNCIL 2004: Draft Charter for Nursing Practice. Pretoria: SANC.

SOUTH AFRICAN NURSING COUNCIL 1993-1998: Disciplinary reports. Pretoria: SANC

TESCH, R 1990: Qualitative research: Analysis types and software tools. New York: The Falmer Press.

VAN VEUREN, P 1993: Kritiese denke as opvoedkundige imperatief. Koers. 58(3):273-282.

WALKER, LO \& AVANT, KC 1995: Strategies for theory construction in nursing. Third edition. Norwalk: Appleton \& Lange. 